\title{
Persuasão ou performance: as estratégias comunicacionais para transformar o rúghi em paixão nacional*
}

\author{
Persuasion or performance: the communicational \\ strategies to transform rugby into a national passion
}

\author{
Persuasión o performance: las estrategias \\ comunicacionales para transformar el rugbi \\ en pasión nacional
}

Marta Regina Garcia Cafeo

- Mestranda do Programa de Pós-Graduação em Comunicação da Universidade Estadual Paulista (Unesp) - Bauru, SP

- Membro do Grupo de Estudos em Comunicação Esportiva e Futebol (Gecef) - CNPq/ Unesp Docente da Faculdade Anhanguera de Bauru

- martacafeo@grafitti.com.br

\section{José Carlos Marques}

- Doutor em Ciências da Comunicação pela Escola de Comunicações e Artes da Universidade de São Paulo (ECA-USP)

- Mestre em Comunicação e Semiótica pela Pontifícia Universidade Católica de São Paulo (PUC-SP)

- Graduado em Letras pela Universidade de São Paulo (FFLCH-USP)

- Docente do Programa de Mestrado em Comunicação e vice-chefe do Departamento de Ciências Humanas da Universidade Estadual Paulista (Unesp) - Bauru, SP

- É líder do Grupo de Estudos em Comunicação Esportiva e Futebol (Gecef) - CNPq/Unesp

- Diretor administrativo da Sociedade Brasileira de Estudos Interdisciplinares da Comunicação (Intercom)

-zeca.marques@faac.unesp.br.

* Este trabalho é uma revisão atualizada de parte da pesquisa apresentada ao grupo de pesquisa "Comunicação e esporte", da Intercom, por ocasião do XXXIV Congresso Brasileiro de Ciências da Comunicação, realizado em Recife (PE), em setembro de 2011. 
Este trabalho analisa a estratégia de comunicação da Confederação Brasileira de Rugby na divulgação do rúgbi no país, com as três fases da campanha de televisão elaborada em conjunto com a fabricante Topper a partir de 2010. Um dos objetivos da entidade é tornar o esporte mais conhecido entre o público brasileiro, tendo em vista a inclusão dessa modalidade na Olimpíada do Rio de Janeiro em 2016. Muito popular nos países de colonização britânica, o rúgbi ainda tem pouca visibilidade no cenário esportivo nacional, algo que se quer transformar com a comunicação organizacional e a publicidade.

PALAVRAS-CHAVE: RÚGBI • PUBLICIDADE • COMUNICAÇÃO ORGANIZACIONAL

\section{Abstract}

This paper analyzes the communication strategy of the Brazilian Rugby Confederation in the promotion of sport in the country, with three television campaigns developed since 2010 together with manufacturer Topper. One of the goals of the organization is to make the sport better known among the Brazilian public, with a view to inclusion of rugby in the Olympics in Rio de Janeiro in 2016. Very popular in countries colonized by Britain, the sport still has little visibility in the national sports scene, something to be transformed in organizational communication and advertising.

KEYWORDS: RUGBY • ADVERTISING • ORGANIZATIONAL COMMUNICATION

\section{Resumen}

Este trabajo analiza la estrategia de comunicación de la Confederación Brasileña de Rugbi en la promoción del rugbi en el país, con las tres fases de la campaña de televisión elaborada en conjunto con el fabricante Topper a partir de 2010. Uno de los objetivos de la organización es hacer que el deporte sea más conocido entre el público brasileño, con miras a la inclusión del rugbi en los Juegos Olímpicos de Río de Janeiro, en 2016. Muy popular en los países colonizados por Gran Bretaña, el deporte todavía tiene poca visibilidad en la escena deportiva brasileña, algo que se pretende transformar por medio de la comunicación organizacional y la publicidad.

PALABRAS CLAVE: RUGBI • PUBLICIDAD • COMUNICACIÓN ORGANIZACIONAL 
$\mathrm{M}$ uito popular nos países de colonização britânica, o rúgbi ainda tem pouca visibilidade no panorama esportivo nacional. Foi contra esse cenário que, no final de 2009, a Associação Brasileira de Rugby (ABR) firmou um patrocínio esportivo com a fabricante de material esportivo Topper, a fim de subsidiar o desenvolvimento das seleções brasileiras (masculina e feminina) da modalidade.

Em 2010, a entidade passou a designar-se Confederação Brasileira de Rugby $(\mathrm{CBRu})$ e, ainda em parceria com a Topper, elaborou um planejamento estratégico e um plano de comunicação para divulgar e fomentar o esporte no Brasil. O objetivo tem sido apresentar o rúgbi para o público brasileiro, aumentar o número de novos atletas e praticantes e ainda atrair novos investimentos. Esse planejamento estratégico alia-se ainda com a inclusão do rúgbi na Olimpíada do Rio de Janeiro em 2016. Não é à toa que a International Rugby Board (IRB), ao lado do Comitê Olímpico Internacional (COI), elegeu o Brasil como prioridade estratégica de desenvolvimento do esporte.

Este trabalho busca analisar a estratégia de comunicação da CBRu e da Topper por meio dos seis filmes publicitários organizados em três fases da campanha e veiculados desde o primeiro semestre de 2010 até o segundo semestre de 2011. Elaborada pela Agência Talent Propaganda para a Topper e com a aprovação da $\mathrm{CBRu}$, a campanha visa à popularização do rúgbi por meio da exposição midiática dessa modalidade esportiva.

\section{BREVE HISTÓRICO DO RÚGBI}

Esporte coletivo com origem nas escolas inglesas na segunda metade do século XIX, o rúgbi é considerado por muitos como "irmão" do futebol - do qual, por circunstâncias históricas, foi separado ainda na infância. De acordo com Franco Júnior (2007, p. 26), "as regras esportivas do rúgbi foram criadas em 1846 e as do futebol, em 1863”. Ambos os esportes, contudo, são o resultado de um conjunto de fatores presentes na Inglaterra do século XIX, como a necessidade de se regulamentar a prática corporal numa sociedade de massa urbana advinda com a Revolução Industrial.

Do mesmo modo, Wisnik (2008, p. 141-142) afirma que "o futebol e o rúgbi nasceram juntos, como gêmeos não idênticos, nas escolas inglesas". A partir da Inglaterra esses esportes foram sendo popularizados para diversos territórios, sendo que o futebol se destacou em praticamente todos os continentes. Já o rúgbi tem grande popularidade na Europa, América do Sul meridional (Argentina, Uruguai e Chile) e em países de colonização britânica, como Canadá, Nova Zelândia, Austrália e África do Sul.

Há várias versões para o surgimento do rúgbi. Uma das lendas relata que em 1823, em uma partida de futebol realizada na Rugby School, o estudante londrino William Webb Ellis, irritado em um jogo de futebol, teria agarrado a 
bola nos braços e corrido o campo todo, o que provocou a ira dos outros jogadores, que tentaram pará-lo, agarrando-o pelo corpo; assim teria nascido o jogo de rúgbi. Em outra versão, como os jogos com bolas sempre estiveram presentes da vida das sociedades, é relatado que entre os anos 1820 e 1830 havia um jogo parecido com o futebol e que permitia carregar a bola com os braços com frequência, o que teria dado origem ao rúgbi. Assim, embora haja diferentes versões para explicar sua origem, o que se pode destacar é que o rúgbi e o futebol nasceram praticamente na mesma época.

O rúgbi foi disputado em quatro das sete primeiras edições dos jogos olímpicos da era moderna. A primeira aparição ocorreu durante a Olimpíada de Paris (1900), voltando a ser disputado na de Londres (1908), na de Antuérpia (1920) e novamente na de Paris (1924). Após esta última edição, o Comitê Olímpico Internacional retirou o esporte do programa olímpico. Oito décadas após sua exclusão da Olimpíada, o mesmo comitê decidiu, em 2009, que o rúgbi, em sua versão Rugby Sevens (disputada por times com sete atletas cada um), seria incluído dos Jogos de 2016, no Rio de Janeiro.

A modalidade é disputada em um campo de cem metros com dois postes (traves) em forma de "H". O objetivo é chegar com a bola oval à linha de in-goal do adversário e marcar o try. A pontuação é basicamente o try (5 pontos), colocando-se a bola na área chamada in-goal (área de dez metros, aproximadamente, atrás da linha de fundo do campo Obtendo um try, a equipe beneficiada com os cinco pontos tem o direito de chutar a bola para a área superior do poste em forma de "H"; se a bola passar por esse espaço, há o que se chama de conversão, o que rende mais dois pontos para a equipe. Na conversão a bola deve ser colocada a qualquer distância de onde o try foi marcado, respeitando a regra de que esteja na mesma direção (perpendicular à linha de fundo) de onde a bola foi "cravada" no momento do try. O objetivo do jogo é marcar o maior número de pontos. Quando a bola sai pela lateral do campo, é cobrado um line-out, no qual os dois times se alinham perpendicularmente à linha de touch (toque) e disputam a bola no alto, que deve ser arremessada em linha reta entra as duas formações, para que a disputa seja justa, com a chance de os dois times pegarem a bola.

No rúgbi só é possível passar a bola com as mãos para trás ou para o lado; para a frente, somente por meio de um chute com os pés. Só se pode tacklear (derrubar) o adversário se ele estiver com a posse de bola, sendo proibido desferir socos e rasteiras, mesmo contra o jogador que está com a posse da bola.

No esporte profissional há duas modalidades: 1) Union, com quinze jogadores com posições, funções e características físicas diferentes. Os jogadores são classificados de acordo com o tipo físico predominante: os forwards (defesa) são geralmente mais pesados e fortes e os ackwards (ataque) são mais leves e velozes. O jogo tem dois tempos de quarenta minutos e scrum com oito jogadores por equipe. 2) Seven a side, com sete jogadores, com dois tempos de sete minutos e scrum com três jogadores por equipe. 
O esporte, praticado em 120 países por mais de 3 milhões de pessoas, é considerado o segundo esporte mais popular no mundo, perdendo apenas para o futebol. A Copa do Mundo de Rúgbi é apontada como o terceiro maior evento esportivo do planeta, ficando atrás apenas da Copa do Mundo de Futebol e da Olimpíada. De acordo com a Internacional Rugby Board (IRB), a Copa do Mundo de Rúgbi de 2007 na França teve audiência de 4 bilhões de espectadores, o que demonstra a força desse esporte em todo o mundo.

\section{BREVE HISTÓRICO DO RÚGBI NO BRASIL}

No Brasil, de acordo com a Associação Brasileira de Rugby (ABR), Charles Miller teria organizado em São Paulo, em 1895, o primeiro time de rúgbi brasileiro. Já a primeira agremiação a praticar o esporte foi o Clube Brasileiro de Futebol Rúgbi, fundado em 1891. Porém, somente em 1925 o rúgbi começou a ser jogado regularmente no Brasil, no Campo dos Ingleses, em Pirituba, na Grande São Paulo, pertencente ao atual Club Atlético São Paulo. Entre o período de 1926 a 1940 foram realizados jogos interestaduais entre as equipes paulistas e cariocas e também jogos internacionais, como contra os Springboks em 1932 e a seleção britânica em 1936.

No período compreendido entre os anos 1941 e 1946, houve a interrupção do esporte por causa da Segunda Guerra Mundial; os jogos só foram retomados em 1947. A partir de 1960, foi formada o Aliança Rugby Footbal Club, com jogadores ingleses, franceses, argentinos e brasileiros do Club Atlético São Paulo. Em 1961 o São Paulo Rugby Football Club, nova equipe de rúgbi, foi formado com membros da colônia japonesa.

Segundo a ABR, somente em 6 de outubro de 1963 foi fundada em São Paulo a União de Rugby do Brasil, com a finalidade de organizar e dirigir o rúgbi brasileiro. Já no ano 1964, a União Rugby patrocinou o III Campeonato Sul-Americano de Rúgbi, no qual o Brasil ficou com o vice-campeonato. A partir daí o esporte começou a ser praticado cada vez mais em escolas de ensino superior. Apesar de caminhar paralelamente ao futebol, até o começo dos anos 1960 o rúgbi era um esporte de elite, praticado em pequenos círculos sociais.

A Associação Brasileira de Rugby (ABR) foi fundada em 20 de dezembro de 1972, em substituição à União de Rugby do Brasil. A ABR foi também uma das fundadoras da Confederação Sulamericana de Rugby (Consur) em 1989. A afiliação à International Rugby Board (IRB), entidade máxima que administra o rúgbi no mundo, só aconteceu em 1999. Em 2010, para adequar a estrutura administrativa da entidade e obter apoio do Comitê Olímpico Brasileiro (COB), a Associação Brasileira de Rugby foi transformada em Confederação Brasileira de Rugby (CBRu). A partir daí elaborou-se um planejamento estratégico que vem captando recursos, patrocinadores e apoiadores para o fomento do esporte no Brasil. 
O presidente da Confederação Brasileira de Rugby, Sami Arap, afirmou que "até o ano passado, o rúgbi era motivo de chacota no Brasil", mas com a entrada da Topper como patrocinadora oficial do rúgbi e os recursos de outras cotas de patrocínios, as seleções masculina e feminina estão conseguindo se estruturar e participar de várias competições. Em fevereiro de 2011, por exemplo, a equipe masculina Brasileira de Rúgbi Seven derrotou a equipe Argentina, no Campeonato Sul-Americano de Rúgbi Seven, realizado em Bento Gonçalves (RS) e conseguiu a classificação para o Pan-Americano em Guadalajara, no México, em 2011. A partida é considerada um marco histórico, pois pela primeira vez no Brasil um torneio de rúgbi no Brasil teve jogos transmitidos ao vivo pela televisão, pelo canal a cabo SporTV.

O rúgbi hoje, no Brasil, segundo a $\mathrm{CBRu}$, é praticado em 22 estados, em mais de 230 clubes, e conta com cerca de 30 mil atletas, com grande presença no meio universitário. Como praticantes fiéis o esporte tem adolescentes e universitários, homens e mulheres entre 16 e 30 anos das classes A e B. Já como seguidores o público é composto por homens e mulheres entre 16 e 60 anos, das classes A e B, que de alguma forma tiveram contato com o esporte e que adotaram o rúgbi como um estilo de vida.

A seleção brasileira feminina de rúgbi é heptacampeã sul-americana e foi a $10^{\mathrm{a}}$ colocada no último mundial, em 2009. Já a seleção masculina brasileira ocupa o $29^{\circ}$ posto do ranking mundial da IRB entre 95 seleções e é a $4^{\text {a }}$ força do rúgbi na América do Sul, ficando atrás da Argentina $\left(9^{\circ}\right)$, Uruguai $\left(22^{\circ}\right)$ e Chile $\left(23^{\circ}\right)$, conforme dados de setembro de 2011.

\section{AS CAMPANHAS DA TOPPER E DA CBRU NA TV BRASILEIRA}

Para Barthes (2009), o esporte é feito para relatar o contrato humano. A humanidade, ao longo da sua existência, tem buscado criar formas (contratos) para relacionar-se com o ambiente e para relacionar comunidades com outras comunidades. Em determinados momentos, as sociedades projetam suas crenças e seus valores nos jogos e nas modalidades esportivas. Ainda segundo Barthes, cada esporte nacional "brota da própria matéria de uma nação", isto é, de seu solo e de seu clima, assim como o hóquei sobre o gelo no Canadá, que possui uma relação direta com os habitantes do território. Por outro lado, o esporte é considerado um fenômeno cultural, estando presente em quase todos os momentos na vida das pessoas. "Pessoas e comunidades podem definir e expressar sua própria identidade e raízes comuns por meio do esporte e dos rituais a ele associados" (Morgan, 2008, p. 64).

1 Entrevista concedida à publicação Meio e Mensagem. Disponível em: http://grupomm.mmonline.com.br/noticias.mm?url=Topper_e_Bradesco_investem_no_potencial_do_rugby_brasileiro. Acesso em: 24 mar. 2011. 
Nesse contexto, como compreender o enorme sucesso do futebol e as dificuldades na disseminação do rúgbi no Brasil, já que ambos os esportes são de origem inglesa e foram apresentados ao país por Charles Miller? Para DaMatta (1982 p. 16), "cada sociedade tem o futebol que merece, pois ela o molda e projeta nele um conjunto de temas que lhe são básicos”. O Brasil, conhecido como o "país do futebol", é o único que participou de todas as copas de mundo e tem cinco títulos mundiais. Já o rúgbi, no país é um esporte com poucos adeptos e com resultados de pouca expressão. O futebol, afirma DaMatta (1982 p. 29), "é um objeto social complexo e que pode ser socialmente apropriado de vários modos em diferentes sociedades". Dessa forma, cada país se apropriou de alguns elementos do futebol e, com os aspectos sociais, desenvolveu suas próprias modalidades esportivas, como, por exemplo, os Estados Unidos, que criaram o futebol americano a partir de elementos retirados do rúgbi.

Diante desse quadro, a Confederação Brasileira de Rugby resolveu encarar o desafio de popularizar o esporte no país: dentro da filosofia definida por Margarida Kunsch (2002, p. 14), elaborou um planejamento estratégico denominado "Projeto 2016 - Eu acredito", com o objetivo de levar o Brasil à elite do esporte:

As organizações devem ter entre os objetivos de comunicação o de buscar o equilíbrio entre os seus interesses e os dos públicos a elas vinculados. Esses objetivos só serão alcançados se a comunicação for planejada de forma estratégica, utilizando técnicas de relacionamento e meios específicos, devidamente selecionados, e integrando todas as atividades comunicações dentro da filosofia de comunicação organizacional integrada.

Para o crescimento e a consolidação da marca Topper, o planejamento elaborado, de longo prazo, envolve a qualidade dos produtos, a criação de uma imagem institucional que alie respeito aos cidadãos e demonstre o comprometimento da empresa com o desenvolvimento de novos esportes, alinhando as questões sociais e aspectos éticos com o mercado.

O ponto de partida depende de uma base ética, ou seja, a empresa conduzir-se com honestidade, seriedade e competência. Dessa forma, será possível promover a confiança de seus funcionários, do consumidor e da sociedade em seus produtos, serviços e atendimento. Em segundo lugar, investir na promoção cultural, esportiva e cientifica também colabora para que se associe a imagem da empresa à de uma instituição útil e vital para a sociedade (Pimenta, 2002, p. 101).

O patrocínio da Topper, uma empresa de material esportivo, na divulgação e popularização do rúgbi, contribui de forma positiva para o seu crescimento e para a busca de novo posicionamento. De acordo com Morgan (2008, p. 291), "no ambiente atual de negócios, quase todos os patrocínios esportivos são tratados como investimentos com uma expectativa de que haja um retorno positivo.” Assim sabe-se que a parceria da Topper com a CBRu também visa contribuir com a imagem institucional da empresa. 
Esse planejamento estratégico tem procurado garantir os investimentos de parceiros e patrocinadores, na busca de financiamentos para o progresso profissional e contínuo das equipes de quinze e de sete atletas. Esse projeto vincula-se a um plano de comunicação que visa criar uma estrutura de competição nacional e a sua consequente divulgação nos meios de comunicação. A CBRu não poupa ousadia ao definir suas metas:

Em 2016 as seleções brasileiras, masculina e feminina, serão reconhecidas como a segunda potência do rugby no continente americano e uma das maiores seleções do mundo inspirando pessoas em torno a uma comunidade que aproveite todas as oportunidades que o esporte apresenta. ${ }^{2}$

Vale destacar que o número de atletas federados no Brasil saltou de 2 mil em 2009 para 10 mil em 2011, demonstrando que o trabalho realizado pela entidade tem contribuído para a disseminação do esporte. Esses resultados podem ser creditados à estratégia de divulgação adotada pela CBRu a partir de 2010, quando teve início uma campanha publicitária veiculada por meio da parceira da entidade e a Topper, com filmes publicitários que visam à popularização do rúgbi com a exposição nos veículos de comunicação. A campanha, até o segundo semestre de 2011, veiculou seis filmes publicitários de trinta segundos, tendo a exibição se dado nos intervalos de jogos de futebol e programas esportivos, nas emissoras de canal aberto Rede Globo, Record e Bandeirantes, e nos canais por assinatura SporTV, ESPN e ESPN Brasil.

$\mathrm{Na}$ primeira fase da campanha foram veiculados dois filmes, nos meses de abril e maio de 2010: Autógrafo e Coletiva. Ambos tinham como foco despertar a curiosidade e atrair a atenção para o esporte, por meio de um enredo de humor para persuadir e conquistar o receptor da mensagem. O período da veiculação, antecedendo a Copa do Mundo de 2010, pode ser considerado estratégico, pois a população brasileira estava mobilizada pelo futebol. As propagandas utilizaram fatos, situações e comportamentos que fazem parte do repertório e da realidade dos jogadores de futebol, para brincar com o fato de o rúgbi ser um esporte desconhecido pela maioria da população.

No filme Autógrafo, uma mulher encontra um homem na rua e pergunta se ele não era "aquele jogador famoso de rúgbi". Ao receber a resposta positiva, ela pede-lhe um autógrafo. Na cena seguinte, percebe-se que a situação havia sido criada artificialmente apenas para o contentamento do jogador, já que ele agradece dizendo "Obrigado, amor". A imagem final mostra os dois dentro do carro e a suposta "fã" contrariada (figura 1) por ter que atender aos caprichos do parceiro - ainda um jogador pouco conhecido pelo público.

2 Cf. <http://www.brasilrugby.com.br/>. Acesso em: 15/06/2011. 


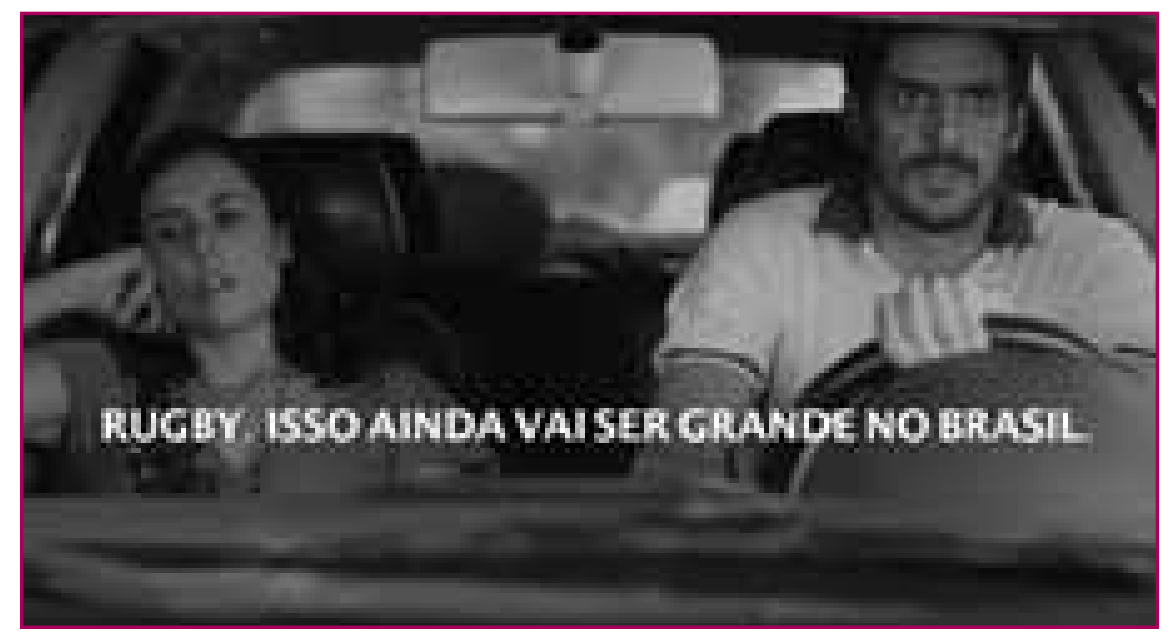

Figura 1

No filme Coletiva, um jogador, um treinador e um assessor de imprensa aparecem atrás de uma bancada e com um painel publicitário às costas, configurando o cenário de uma coletiva de imprensa em algum ambiente esportivo. Ouve-se a locução em off de uma pergunta para o treinador, provavelmente elaborada por algum jornalista. Após a resposta, o assessor de imprensa pede que outra pessoa formule a próxima questão. Nova cena mostra um único jornalista e diversas cadeiras vazias no recinto (figura 2): ao contrário do futebol, por exemplo, o rúgbi ainda não atrai a atenção da imprensa esportiva.

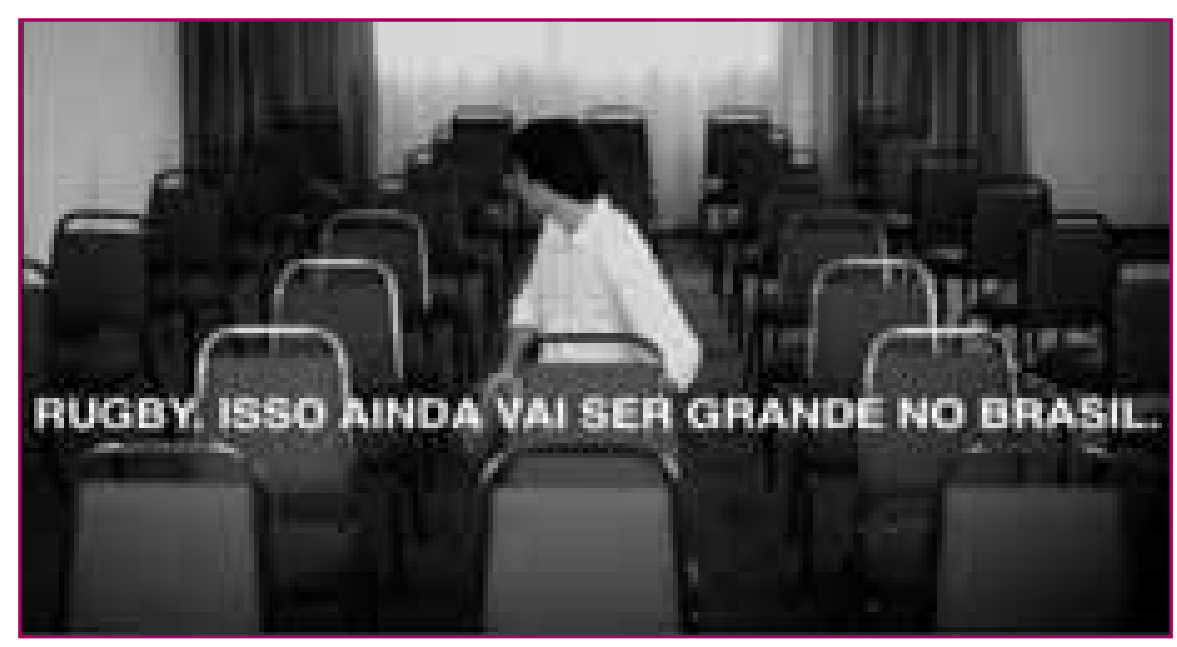

Figura 2 
Nos dois filmes, utilizou-se uma linguagem bem humorada e autodepreciativa, sem praticamente qualquer informação sobre o esporte, mas com situações engraçadas que procuravam despertar o interesse do público. O slogan utilizado ("Rugby. Isso ainda vai ser grande no Brasil") pode ser visto como algo forte e audacioso, comprovando a ideia de que a Confederação Brasileira de Rugby e a Topper decidiram utilizar uma estratégia ousada em busca do desenvolvimento e da popularização do esporte no Brasil.

A segunda fase da campanha começou a ser veiculada em setembro de 2010. Os filmes publicitários apresentaram elementos novos para despertar a curiosidade e atrair ainda mais a atenção para o esporte. O enredo de humor utilizado na primeira fase da campanha continuou e foram apresentados resultados de jogos comparando a evolução do rúgbi brasileiro diante da Argentina, do Chile e do Uruguai, países sul-americanos que estão na frente no Brasil no ranking mundial do esporte. Os filmes foram intitulados Fatos Argentina, Fatos Uruguai e Fatos Chile.

Os três filmes publicitários utilizam o mesmo personagem, objetos e infográficos semelhantes: um homem com tom sisudo, vestido de terno e gravata, aparece sentado numa poltrona à beira de um campo gramado. A medida que ele inicia as comparações entre o Brasil e os adversários sul-americanos, um elemento infográfico aparece na tela, para fornecer as informações do crescimento do rúgbi brasileiro, sempre em comparação com os países vizinhos (figura 3).

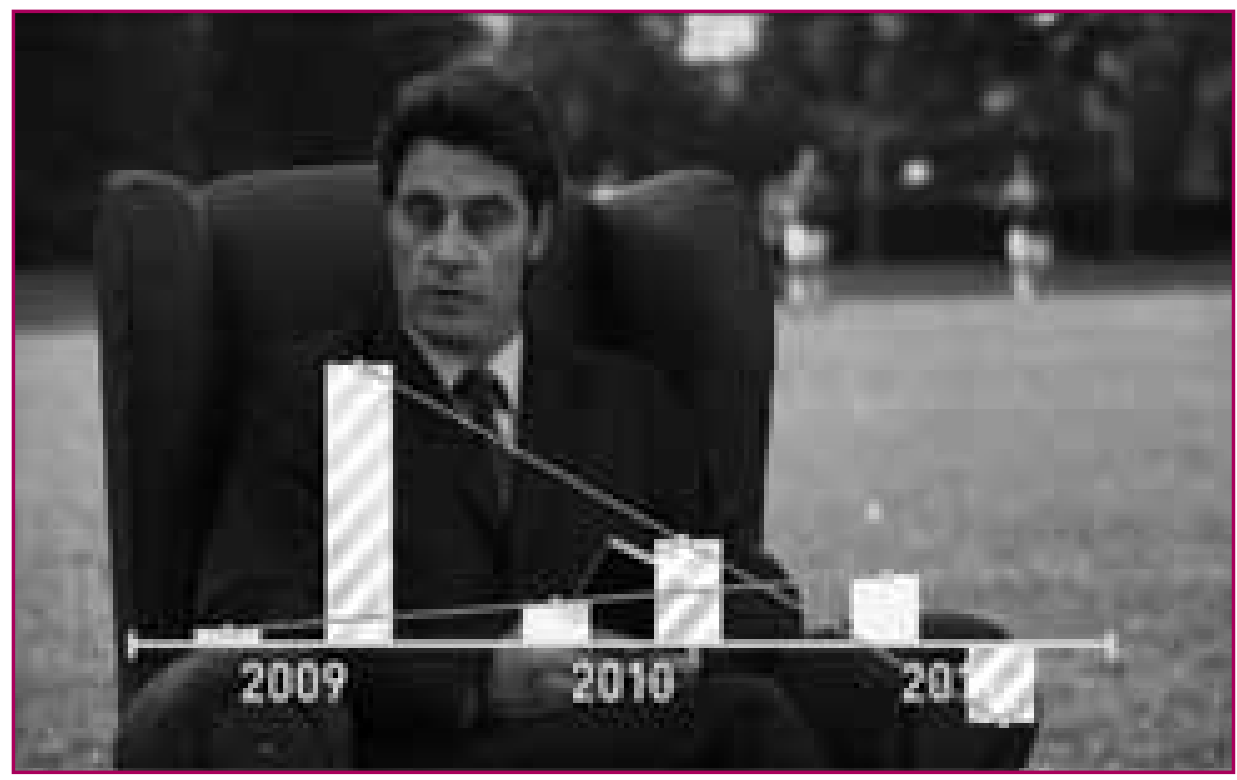

Figura 3 
O que temos aqui é um raciocínio por meio do sofisma (mecanismo discursivo que utiliza a lógica e a dedução, porém calcado em premissas falsas, a fim de persuadir o interlocutor por meio de um raciocínio que o induz ao erro). O telespectador é levado a acreditar que o rúgbi nos outros países está estagnado e no Brasil está em plena ascensão, valorizando-se assim o trabalho que vem sendo desenvolvido pela CBRu. O destaque da campanha são os resultados dos jogos, apresentados com uma linguagem bem-humorada, já que o Brasil permanece como perdedor, mas com melhoria no desempenho em relação aos anos anteriores.

Nessa segunda fase, aparecem pela primeira vez algumas jogadas de rúgbi, que apesar de estarem em segundo plano, foram inseridas nos filmes, permitindo uma maior divulgação do esporte. O slogan utilizado é o mesmo e continua demonstrando o empenho da confederação no fomento do esporte. O que chama a atenção é o fato de as imagens, num primeiro momento, nos fazerem crer que estamos diante de um campo de futebol. Os três filmes publicitários se encerram mostrando um chute em uma bola de rúgbi e uma perna de um jogador com uma chuteira da marca esportiva Topper (figura 5). A imagem procura aproximar o rúgbi novamente do futebol, esporte jogado muito mais com as mãos do que com pés - ao contrário do rúgbi.

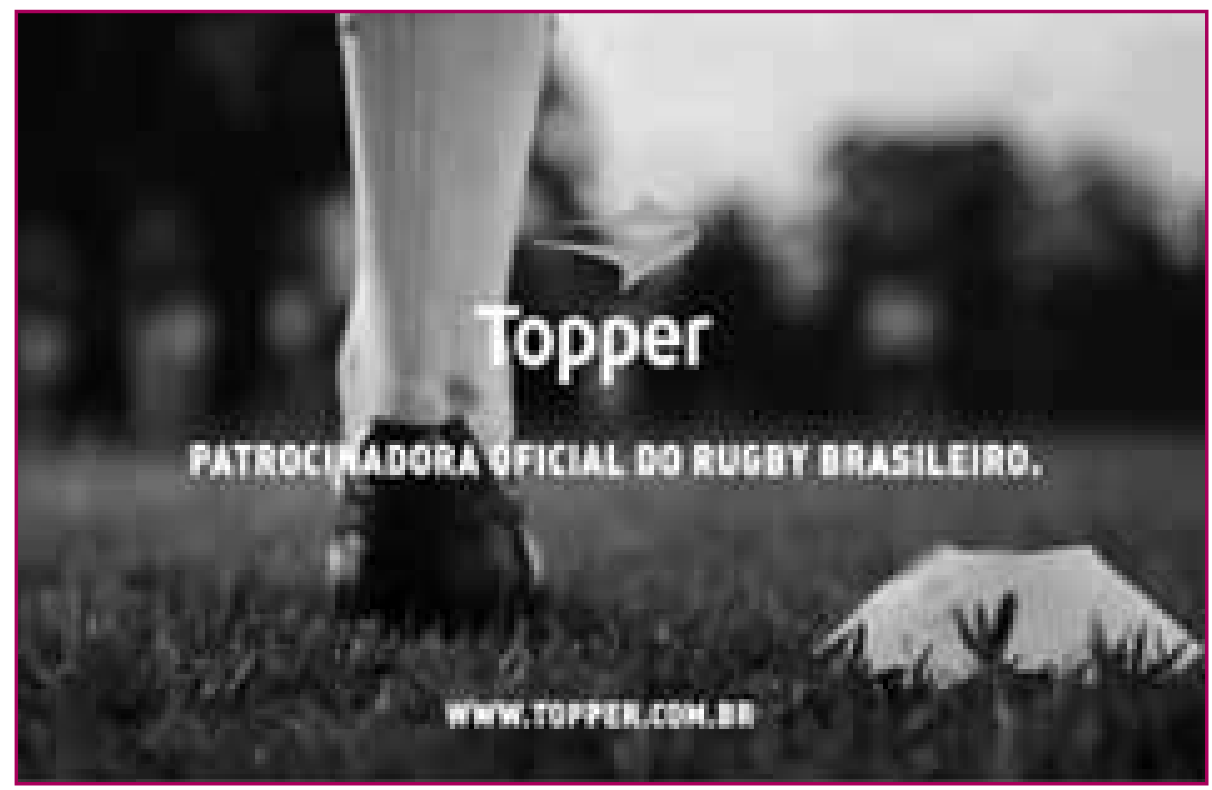

Figura 4

Já a terceira fase da campanha constitui-se de um filme que começou a ser veiculado na TV Bandeirantes em junho de 2011 e que foi intitulado Maria Chu- 
teira. Aqui, o mesmo homem de paletó e gravata, sentado na mesma poltrona à beira de um campo gramado, celebra a classificação da Seleção Brasileira de Rúgbi para o Pan-Americano em 2011, após vencer a seleção da Argentina pela primeira vez na história.

Na continuação é apresentada a primeira "Maria Chuteira"3 do esporte, a Karen Cristina. A retórica do humor é novamente utilizada, já que a "Maria Chuteira" em questão pronuncia a frase "Eu sempre adorei o râbigui", causando o espanto do dirigente diante da pronúncia equivocada do próprio nome do esporte. O slogan permanece inalterado (figura 5).

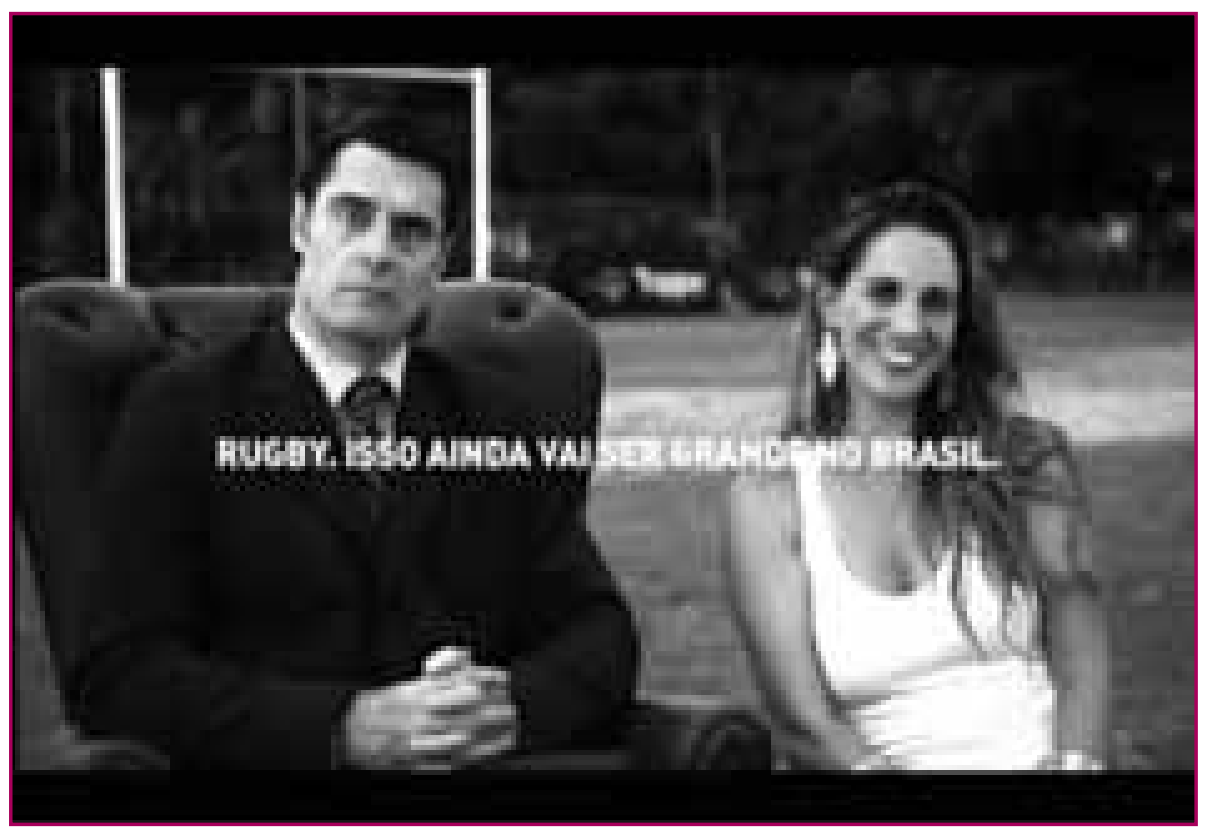

Figura 5

Na segunda e na terceira fase da campanha, a última imagem dos filmes publicitários apresenta a logomarca da Topper com a assinatura "Patrocinadora oficial do rugby brasileiro", dando credibilidade e demonstrando que uma marca esportiva reconhecida e forte está apoiando e incentivando o esporte. Os times brasileiros de futebol, na sua grande maioria, são patrocinados por marcas esportivas de destaque, o que demonstra a proposta da comunicação de criar vínculos entre os esportes.

30 termo refere-se de forma estereotipada e preconceituosa às mulheres que procuram relacionar-se com jogadores de futebol em busca de vantagens financeiras. 
A sonorização final de todos os seis filmes realizados até o segundo semestre de 2011 termina com uma alusão ao batimento cardíaco, o que denota a pulsação do esporte em torno de movimento e paixão, algo que no Brasil só é representado na maioria das vezes pelo futebol:

Ao produzirem um texto para se comunicar, as pessoas utilizam a linguagem verbal e outros sistemas semióticos (como as imagens) com três funções básicas: construir o referente ou universo de discurso ou mundo do qual seu texto fala (função de mostração), estabelecer os vínculos socioculturais necessários para dirigir-se ao interlocutor (função de interação) e distribuir os afetos positivos e negativos cuja hegemonia reconhece e/ ou quer ver reconhecida (função de sedação) (Pinto, 2002, p. 65).

\section{A POPULARIZAÇÃO DO RÚGBI NO BRASIL: ALGUMAS REFLEXÕES}

Os filmes publicitários veiculados na televisão brasileira têm como proposta criar "uma posição" de destaque na mente consumidor, utilizando para tanto a retórica do humor e da aproximação com o futebol. Será isso suficiente para transformar o rúgbi em uma paixão nacional? Qual a retórica mais assertiva para popularizar o esporte? Quais dificuldades e desafios serão enfrentados? O uso de um humor autodepreciativo não seria nocivo ao próprio rúgbi brasileiro? A proposta deste estudo não é esgotar o assunto, mas levantar algumas reflexões.

Para Propp (1992), a comicidade costuma estar associada ao desnudamento de defeitos, manifestos ou secretos, daquele ou daquilo que suscita o riso. $\mathrm{O}$ riso nasce da observação de alguns defeitos no mundo em que o homem vive. O cômico é determinado pela presença de algo menor e defeituoso e ainda como forma de o homem que ri sentir-se enaltecido, pela consciência de que não possui o defeito que provoca o riso. Este, porém, surge diante dos defeitos alheios desde que estes não sejam excessivos, a ponto de causar repugnância, perturbação ou indignação. O riso é suscitado por certa duração inconsciente que parte do visível para se chegar ao que se esconde atrás da aparência:

O riso surge quando a esta descoberta se chega de repente e de modo inesperado, quando ela tem o caráter de uma descoberta primordial e não de uma observação cotidiana e quando ela adquire o caráter de um desmascaramento mais ou menos repentino (Propp, 1992, p. 175).

Ao rir-se de si mesmo, o rúgbi brasileiro - por meio da estratégia da CBRu pode estar criando maior empatia com o público que não conhecia essa modalidade esportiva e que, por meio do humor, começa a olhar para o esporte com maior boa vontade. 
Por outro lado, parece-nos um contrassenso a Confederação Brasileira de Rugby utilizar o termo rugby (em inglês) em toda a sua comunicação (inclusive em seu próprio nome), demonstrando que abdicou dos termos já aportuguesados - râguebi ou rúgbi -, como utilizado pelos veículos de comunicação. O termo em inglês pode causar estranhamento para a maioria da população brasileira e essa vinculação com o elemento estrangeiro pode dar a noção de que se trata de um esporte "caro" e impraticável pelas massas, o que é corroborado pelo perfil dos praticantes do esporte no Brasil (as classes A e B). Além disso, no rúgbi os termos utilizados na sintaxe do jogo são todos em inglês, o que contribuiu para a dificuldade de compreensão do esporte, que tem muitas jogadas de força e de solo, o que muitas vezes causa muita estranheza e desconforto para quem está acostumado com as partidas de futebol. Em muitos momentos é impossível ver a bola, objeto de adoração nas partidas de futebol.

A estratégia de comunicação utilizada nos filmes publicitários, de brincar com o humor pelo fato de o esporte não ser conhecido, e ainda com situações e comportamentos que fazem parte do repertório e da realidade dos jogadores de futebol, demonstra a intenção da aproximação do rúgbi com o futebol. Porém, há muitos elementos distintos entre uma partida de rúgbi e uma de futebol. No rúgbi, a bola oval quase não tem vida própria, pois na maior parte do tempo é carregada pelos jogadores com as mãos. No futebol a bola é chutada e permanece visível quase que todo o tempo da partida, sendo por isso referenciada do começo ao fim.

Com a volta do rúgbi aos jogos olímpicos na edição do Rio de Janeiro em 2016, a Seleção Brasileira de Rugby já tem a vaga garantida. Uma boa performance da equipe pode contribuir para o fomento do esporte, já que o Brasil valoriza muito os vencedores. Porém, até 2016 o esporte terá um longo caminho e diversos desafios, que passam pela reestruturação das equipes, a valorização dos campeonatos nacionais e estaduais e ainda a conquista de espaço para a divulgação do rúgbi nos meios de comunicação.

Como atualmente no Brasil os canais de televisão aberta nunca transmitiram uma partida de rúgbi de equipes brasileiras, a comunicação do esporte somente por meio de filmes publicitários com a duração de trinta segundos pode encontrar uma dificuldade na efetivação da mensagem para um telespectador que nunca teve contato com a modalidade esportiva. Eventos esportivos como o Pan-Americano, cuja edição de 2011 será transmitida em canal aberto pela TV Record, podem apresentar a modalidade para uma grande parte da população brasileira que não tem acesso aos canais de tevê a cabo.

A par de tudo isso, diversos projetos com crianças visando popularizar o esporte estão sendo desenvolvidos em todo o país, demonstrando os valores pregados pelo rúgbi, como disciplina, coragem, camaradagem, lealdade, ética, controle e jogo limpo. Iniciativas como esta foram utilizadas também por outros esportes na busca pelo crescimento no cenário nacional. 
A parceria da Topper com o rúgbi no Brasil faz parte da estratégia de comunicação organizacional da empresa, já que no início de 2010 a São Paulo Alpargatas S.A - detentora da marca - elevou sua participação para 70,7\% do capital social da Alpargatas Argentina. Essa empresa desempenha papel importante na estratégia de internacionalização da Alpargatas, especialmente a de aumentar a participação da Topper no mercado latino-americano de artigos esportivos. A Topper é líder na Argentina, onde 51,0\% dos lares possuem pelo menos um par de calçados da marca.

Segundo Brandão (2009, p. 3), a comunicação organizacional

tem como objetivo primeiro o mercado, visando atingir os diversos públicos das corporações com o intuito de vender - seja uma imagem, seja um produto, seja uma ideia, seja uma fé - e obter lucro financeiro, pessoal, em status ou poder. Para isso, utilizar-se-á todo o arsenal de instrumentos e tecnologias de comunicação de massa, de grupo e interpessoal, complementando com técnicas de pesquisas diversas (...), bem como de todo o conjunto de conhecimentos e técnicas das áreas de marketing e de comunicação organizacional.

A Alpargatas investe atualmente na marca Topper para torná-la uma das grandes marcas esportivas do Brasil, status já alcançado na Argentina. De acordo com os resultados consolidados da companhia divulgados no quarto trimestre de 2010,

a posição no segmento de futebol foi fortalecida por meio do lançamento de produtos como a chuteira "The one professional" e os calçados, bolas e camisas de seleções que participaram da Copa do Mundo. Os investimentos se estenderam ao marketing esportivo com o patrocínio do Atlético Mineiro, do Grêmio, da Confederação Brasileira de Futsal, da Federação Paulista de Futebol e do Campeonato Paulista, além do apoio direto a atletas. A marca estreou em outras modalidades esportivas com o lançamento de produtos para o $\mathrm{ru}$ gby, o tênis e o running. Topper passou a ser a marca que apoia diretamente alguns dos principais projetos do Instituto Alpargatas. Com o projeto Topper "Educação por Meio do Esporte", 62,0 mil crianças foram beneficiadas em ações de inclusão por meio da prática esportiva no ambiente escolar. ${ }^{4}$

A publicação Meio e Mensagem on-line, em dezembro de 2010, havia selecionado as dez campanhas mais comentadas na internet, no Twitter, em blogs e sites especializados. Após uma análise editorial, foi avaliada a criatividade das campanhas, bem como a repercussão, a lembrança e os conceitos utilizados. A campanha da Topper/Rugby ficou entre as dez finalistas de "Melhor campanha do ano 2010", e em votação realizada no site ficou em terceiro lugar. Já o filme Fatos Uruguai foi shortlist no Festival de Cannes de 2011. Essa exposição do rúgbi em diferentes esferas do mercado publicitário intensificou-se no final do mês de setembro de 2011, quando a Topper lançou o hotsite Mundo Rugby

4 Disponível em: <http://admin.valoronline.com.br/sites/default/files/valor_ri/21-03_alpargatas_capa_c.pdf $>$. 
(www.topper.com.br/mundorugby), com informações sobre o esporte, dentro da sua proposta de comunicação integrada.

\section{CONSIDERAÇÕES FINAIS}

Desse modo, acreditamos que todos os aspectos retratados sejam importantes para a estratégia da campanha, que visa fazer do rúgbi uma paixão nacional. E esses elementos não se esgotam nesta breve análise. Cabe aos dirigentes do esporte e às empresas patrocinadoras e parceiras (responsáveis pelos projetos) buscarem formas assertivas de se comunicar e disseminar o esporte no Brasil.

Talvez ainda seja cedo para averiguarmos a validade e o retorno da campanha da CBRu em parceria com a Topper para a real popularização do esporte no país. Mas sabe-se que a campanha realizada vem repercutindo e contribuindo para o aumento do número de atletas federados e também para a construção de imagem da marca Topper no Brasil. De todo modo, cabe destacar que a principal estratégia da entidade, na tentativa de tornar o rúgbi mais difundido entre o público brasileiro, está alicerçada num plano de comunicação ousado, o qual vem empregando o riso e a aproximação com o universo do futebol para popularizar uma modalidade identificada como algo elitista e complexo para a maioria da população brasileira.

\section{REFERÊNCIAS}

ALPATRGATAS. Resultados consolidados 2010 da Alpargatas. Disponível em: <http://admin.valoronline.com.br/sites/default/ files/valor_ri/21-03_alpargatas_capa_c.pdf >. Acesso em: 21 out. 2011.

ASSOCIAÇÃO Brasileira de Rugby. 0 rúgbi. Disponível em: <http://www.brasilrugby.com.br/Rbrasil.htm>. Acesso em: 24 jun. 2011. BARTHES, Roland. 0 que é o esporte? Revista Serrote, n 3, São Paulo, Instituto Moreira Salles, 2009.

BRANDÃo, Elizabeth. Conceito de comunicação pública. In: DUARTE, Jorge. (Org.). Comunicação pública: estado, mercado, sociedade e interesse público. 2. ed. São Paulo: Atlas, 2009.

CAILLOIS, Roger Os jogos e os homens. Lisboa: Editora Cotovia, 1990.

CONFEDERAÇÃO Brasileira de Rugby. Disponível em: <http://www.brasilrugby.com.br/>. Acesso em: 15 jun. 2011.

DaMATTA, Roberto et al. (Org.). Universo do futebol: esporte e sociedade brasileira. Rio de Janeiro: Edições Pinakotheke, 1982. FRANCO JÚNIOR, Hilário. A dança dos deuses: futebol, cultura, sociedade. São Paulo. Companhia das Letras. 2007.

HUIZINGA, Johan. Homo ludens. São Paulo: Perspectiva, 2000.

INTERNACIONAL Rugby Board. Disponível em: <http://www.irb.com/rankings/full.html>. Acesso em: 05 jun. 2011.

KUNSCH, Margarida M. Krohling. Planejamento de relações públicas na comunicação integrada. 2. ed. Summus Editorial, 2002. MORGAN Melissa Johson; SUMMERS Jane. Marketing esportivo. São Paulo: Thomson Learning. 2008.

PIMENTA, Maria Alzira. Comunicação empresarial. 3. ed. Campinas: Alínea, 2002.

PINTO, Milton José. Comunicação e discurso: introdução a analise de discursos. 2. ed. São Paulo: Hacker Editores, 2002.

PROPP, Vladímir. Comicidade e riso. São Paulo: Ática, 1992.

WISNIK, José Miguel. Veneno remédio: o futebol e o Brasil. São Paulo: Companhia das Letras, 2008.

Recebido em: 12.09.2011 / Aceito em: 31.10.2011 